\title{
Problems Encountered While Dressing and Undressing by Persons with Upper Amputated Limb
}

\author{
N. Pruthi, P. Seetharaman and Chanchal \\ Department of Clothing \& Textiles, CCS Haryana Agricultural University, Hisar 125 004, \\ Haryana, India \\ Telephone: 01662-244459; Email: akpruthi@hau.nic.in
}

KEYWORDS Disabled; functional garments; problems; clothing

\begin{abstract}
Thirty respondents (29 men and one women) with upper amputated limbs were interviewed and observed to identify their problems while dressing and undressing. The problems encountered by them while dressing/ undressing were: fastening/unfastening of placket and cuffs, tucking of shirt, sleeves of amputated side keep hanging if prosthesis not used, inconvenient to use front pocket of left side by right limb amputee, setting lower garments at waist, fastening of pants' belt fly's zipper, tying/untying of string and setting of dhoti. The problems encountered by women are fastening/unfastening of fasteners, setting of lower garments at waist, tying/untying of string and setting of saree.
\end{abstract}

\section{INTRODUCTION}

Clothing which is designed and constructed in accordance with physical limitations is very important for the physically impaired people. There is no doubt that exact problems of the handicapped are related to the type of disability and are highly individualized but a few commonly shared clothing requirements are appearance, safety, comfort, independence, durability and availability of suitable garments. With this view Reich (1980) classified the handicaps with common physical limitation groups to suggest a way to deal with their clothing related needs. The information substantiated that most of the special needs of one group varied from those of another and relationship also existed between the common physical limitation group and their clothing needs. Therefore, an endeavour was made to analyse the clothing related problems of the upper limb amputees critically to recommend functional features for their garments because amputation in any part of upper limb leads to physical impairment creating hindrance in dressing and undressing.

\section{METHODOLOGY}

In a study conducted on 200 handicapped persons, 60 were amputees. Among amputees, 30 respondents had amputation in their upper limbs while 30 respondents had amputation in their lower limbs. Amongst upper limb amputees, 29 were men and one was woman. Interview and observation method was used to identify their clothing related problems.

\section{RESULTS ANDDISCUSSION}

Problems Encountered and Help Obtained While Dressing and Undressing

Men with Upper Amputated Limb: The data presented in Table 1 regarding upper garments indicated that all the upper limb amputees faced problems in 'fastening of placket fasteners' whereas a few of them $(37.93 \%)$ reported that 'unfastening of placket fasteners' was also a difficult task. However, help was obtained rarely since they had learnt over the years to manage themselves inspite of their difficulties. All those respondents $(44.83 \%)$ who had cuffs in their dresses faced problems in 'fastening/unfastening the cuffs' fasteners' of their functional hand only as it could not be done with amputated limb. So for this activity, help was obtained to a greater extent $\left(\bar{x}_{\mathrm{w}}=1.53\right)$ but a few of them preferred to leave their cuffs open.

It is evident from the data regarding lower garments that a majority of upper limb amputees $(86.2 \%)$ encountered problems in 'setting the garment at waist' whereas rest of the respondents $(13.8 \%)$ had no problem as they were either using elastic or could manage with the amputated fingers. For problem of 'setting garment at waist', the respondents rarely sought help $\left(\bar{x}_{\mathrm{w}}=0.65\right)$. The respondents $(44.83 \%)$ who wore pants, faced problems while 'tucking the shirt' and 'fastening of pants' belt', which were generally sorted out 
with others' help $\left(\bar{x}_{\mathrm{w}}=1.5\right)$. 'Tying of string' was a problem for all those respondents $(75.86 \%)$ who used string in their lower garments for which help was rarely obtained $\left(\bar{x}_{w}=0.5\right)$. 'Untying of string' was found difficult by 27.51 per cent respondents who were assisted rarely $\left(\bar{x}_{w}=0.6\right)$. 'Fastening/ unfastening of fly's zipper' was reported to be a difficult task by a few respondents (17.24\%). Assistance was required more frequently during 'fastening of zipper' $\left(\bar{x}_{\mathrm{w}}=0.69\right)$ than 'unfastening' $\left(\bar{x}_{\mathrm{w}}=0.2\right)$. 'Unfastening of pants' belt' was the problem reported by very few respondents $(3.45 \%)$ who were not taking any help. A few respondents $(17.24 \%)$ were using dhoti which was worn with others' help most of the times $\left(\bar{x}_{\mathrm{w}}=1.6\right)$.

Women with Upper Amputated Limb: There was only one woman with upper amputated limb who did not face any problem with the upper garments (Table 2) since her garments were without any placket or fasteners. She faced some problems with her lower garments while 'tying/untying of string' for which help was obtained rarely $\left(\bar{x}_{\mathrm{w}}=1\right)$. 'Setting of garments at waist' was found to be difficult. However, no help was sought by this respondent.

From the data, it can be concluded that slipping on and removing garments was not a problem for upper limb amputees inspite of one functional hand. However, manipulation of fasteners was a great problem for which help was obtained. To solve the problem of cuffs' fasteners the respondents had stopped wearing dress with cuffs. More than 50 per cent respondents were not wearing pants-shirt because of fastening problems and had adopted kurta-pyjama. But there were few dhoti wearer who did not adopt any other dress inspite of dependency on others while dressing/ undressing.

To solve the problem of upper limb amputees functional features were incorporated in the most commonly used dresses. The modified dresses were assessed for suitability and acceptability to recommend the functional features. Recommended functional features are:

1. To solve the problem of fastening/ unfastening of fasteners:

- Preferably make small placket to have minimum number of fasteners.

- Use easy sliding zipper or big press buttons for small plackets.

2. For prosthetics (using artificial limb)

- Make elasticated cuffs

- Keep 5 inches placket along sleeve seam on amputated side and fasten it with zipper.

- Make a loop on the cuff of nonamputated side.

Table 1: Men with upper amputated limb: problems encountered and help obtained while dressing and undressing

\begin{tabular}{|c|c|c|c|c|c|}
\hline \multirow[t]{2}{*}{ S. No. } & \multirow[t]{2}{*}{ Dressing/ undressing procedure } & \multicolumn{3}{|c|}{ Problems encountered } & \multirow{2}{*}{$\begin{array}{l}\text { Help obtained } \\
\qquad W M S\left(\bar{x}_{\mathrm{w}}\right)\end{array}$} \\
\hline & & Yes & No & $N A$ & \\
\hline \multicolumn{6}{|c|}{ 1. Upper Garments } \\
\hline i) & Slipping hands in sleeves & - & $29(100.00)$ & - & 0 \\
\hline ii) & Slipping garments over head & - & $29(100.00)$ & - & 0 \\
\hline iii) & Manipulation of placket fasteners & $29(100.00)$ & - & - & 0.24 \\
\hline iv) & Manipulation of cuffs' fasteners & $13(44.83)$ & - & $16(55.17)$ & 1.53 \\
\hline v) & Unfastening of cuffs' fasteners & $13(44.83)$ & - & $16(55.17)$ & 1.53 \\
\hline vi) & Unfastening of placket fasteners & $11(37.93)$ & $18(62.07)$ & - & 0.63 \\
\hline vii) & Removing garments off the head & - & $29(100.00)$ & - & 0 \\
\hline viii) & Removing garments off the arms & - & $29(100.00)$ & - & 0 \\
\hline \multicolumn{6}{|c|}{ 2. Lower Garments } \\
\hline i) & Slipping legs in garments & $24(82.86)$ & - & $5(17.24)$ & 0 \\
\hline ii) & Setting garments & $25(86.20)$ & $4(13.8)$ & - & 0.65 \\
\hline iii) & Tucking of shirt & $13(44.83)$ & - & $16(55.17)$ & 0.84 \\
\hline iv) & Fastening of pants' belt & $13(44.83)$ & - & $16(55.17)$ & 0.84 \\
\hline v) & Fastening of fly's zipper & $5(17.24)$ & $8(28.89)$ & $16(55.17)$ & 0.69 \\
\hline vi) & Tying of string & $22(75.86)$ & - & $7(24.14)$ & 0.5 \\
\hline vii) & Untying of string & $8(27.51)$ & $14(48.28)$ & $7(24.14)$ & 0 \\
\hline viii) & Unfastening of pants' belt & $1(3.45)$ & $12(41.38)$ & $16(55.17)$ & 0 \\
\hline ix) & Unfastening of fly's zipper & $5(17.24)$ & $8(27.59)$ & $6(55.17)$ & 0.2 \\
\hline $\mathrm{x})$ & Tying of dhoti & $5(17.24)$ & - & $24(82.76)$ & 1.6 \\
\hline
\end{tabular}

Figures in parenthesis show percentage; WMS $\left(\bar{x}_{\mathrm{w}}\right)=$ Weighted mean score weighted by frequency. 
Table 2: Women with upper amputated limb: problems encountered and help obtained while dressing and undressing

\begin{tabular}{|c|c|c|c|c|}
\hline \multirow[t]{2}{*}{ S. No. $\quad$ Dressing/ undressing procedure } & \multicolumn{3}{|c|}{ Problems encountered } & \multirow{2}{*}{$\begin{array}{c}\text { Help obtained } \\
W M S\left(\bar{x}_{w}\right)\end{array}$} \\
\hline & Yes & No & $N A$ & \\
\hline \multicolumn{5}{|l|}{ Lower garments } \\
\hline i) Slipping legs in garments & $1(100.00)$ & - & - & 0 \\
\hline ii) Setting garments at waist & $1(100.00)$ & - & - & 0 \\
\hline iii) Tying of string & $1(100.00)$ & - & - & 1 \\
\hline iv) Untying of string & $1(100.00)$ & - & - & 1 \\
\hline v) Removing garments off the legs & - & $1(100.00)$ & - & 0 \\
\hline vi) Setting of saree & - & - & $1(100.00)$ & 0 \\
\hline
\end{tabular}

Figures in parenthesis show percentage; WMS $\left(\bar{x}_{\mathrm{w}}\right)=$ Weighted mean score weighted by frequency.

3. For non-prosthetics: fold the sleeves and fasten with fasteners or keep short sleeves to avoid hanging of sleeves.

4. To facilitate tucking, use elastic at waist level or make short shirt with half placket and side slits to avoid tucking.

5. Make pocket on both sides.

Lower Garments

1. To hold the plants in position while setting at waist and fastening of pants' belt use elastic along front belt of the pants, stitched at side seam.

2. For easy dressing of lower garments make loops on front side of pants/pyjama.
3. Use easy sliding zipper in fly.

4. To solve the problem of tying/untying.

- Use elastic in nepha of pyjama.

5. Make back pockets on both sides.

6. Make elasticated dhoti for dhoti wearer.

\section{REFERENCES}

Agarwal, Mamta. 1993. Suitability of Designed Garments for Orthopaedically Handicapped Adult Males. Hisar, India: CCS Haryana Agricultural University, Hisar.

Reich, N. and E. Shanon. 1980. "Handicap: Common physical limitations and clothing related needs." Home Economics Research Journal, 8(6): 437-444. 